\title{
Promoting Performance of the Building Construction Industry through Risk Identification: A Case of Exchequer Funded Building Construction Projects in Machakos County, Kenya
}

\author{
John Malu Nzioki and Mary Nyawira Mwenda
}

\begin{abstract}
Project failure is an increasingly worrying challenge in Kenya. In implementation of exchequer funded building construction projects, the challenge is real. The study examined the influence of risk management practices on the performance of exchequer funded building construction projects in Machakos County. Little research has been conducted on risk identification and its influence on performance of exchequer funded building construction in Machakos County, this study intended to on build onto the already existing body of knowledge. The study was informed by Agency theory and it employed a descriptive survey research design. The target population was 585 National Construction Authority registered contractors and sample size was 232 respondents. In this case the sample selected is deemed to be representative enough of the whole population and therefore valid and genuine generalizations can be made. Methodology involved in collection and analysis of primary data. Descriptive and inferential statistics were used to analyze data. Quantitative data was tabulated and analyzed using frequencies, percentages, means and standard deviation. Test statistics computed to establish degree of relationship between the variables was Fisher test. The findings depict that risk identification leads to the performance of exchequer funded building construction Projects by factor of 0.237 with $P$ values of 0.008 . At $5 \%$ level of significance and $95 \%$ level of confidence, this is statistically significant as the P-Value is lower than 0.05 . The results for testing the hypothesis were $(P=0.008<0.05)$ as the $P$-Value is lower than 0.05 . The study therefore rejects the null hypothesis. The study concludes that there is significant positive relationship between that risk identification leads to the performance of exchequer funded building construction Projects. Further research can be done to assess the risk identification in other county governments and national government projects in Kenya and other countries in order to establish whether the explored factors can be generalized to influence the performance of exchequer funded building construction Projects. The findings of this paper will be used to serve as a longer-term safeguard against risks in construction of buildings in Kenya.
\end{abstract}

Index Terms - Building Construction Projects, Exchequer Funded Projects, Risk Management Practice.

\section{INTRODUCTION}

Many scholars have come up with different definitions of risk identification with an aim of trying to explain its meaning and what it entails. Ideally, risk identification

Published on December 30, 2020.

John Malu Nzioki, MA Candidate, Department of Open Learning, University of Nairobi, Kenya.

(corresponding e-mail: kwaleaegis@ ${ }^{@ m a i l . c o m) ~}$

Mary Nyawira Mwenda, Lecturer, Department of Open Learning, University of Nairobi, Kenya.

(e-mail: mmwenda@ ${ }^{@}$ uonbi.ac.ke) involves all measures that tame all potential risks that might occur within a project.

Risk identification is found in the first stage of risk management process [23] in which it forms a base for conducting other risk management process like risk analysis, risk control and it also gives a platform for organizations to outline areas that are prone to risks. To add to this, if risk identification is conducted accurately, then successful risk management is ensured, and unknown sources of losses and unmanageable occurrence are tamed [31]. There are two types of risk namely, positive risks and negative risks. These risks have significant impact on the project if at all they are not address. On many occasions, risk management team fails to identify both negative and positive risks. Basically, the effect of non-identification of both positive and negative risks is at equilibrium [31]. To sum up, risk identification is the compilation of activities that enables organization to know when and where risk is likely to occur in their project [31].

Primary project document is one of the vital tools that are utilized in risk identification. Apart from this, project management plan and scope statement should be available in order to exhaustively disorient potential risks that are anticipated to occur. Risk management plan and organizational atmosphere forms the environment for risk management, and they should be keenly evaluated in order to conventionally carry out risk identification. To add to this, risk management plan identifies specific risks identification practices that are either favored or outlawed by the organization. According to [16], "all this information can encourage thinking about different risk issues and concerns when evaluated using the tools and techniques of risk identification. The tools and technology that are employed in RI are as varied as the projects they serve. Nevertheless, some groups of tool and technique types are most frequently used."

In construction industry, risk identification is one of the major aspects that is put into consideration before and after the completion of the project. Ideally, it is vital because construction projects are complex and dynamic [1]. In the recent past, many buildings have been collapsing due to lack of proper risk identification. Eventually, construction projects are naturally hazarding industries hence more efforts should be channeled to risk identification programs [34]. In order to accomplish project objectives and targets, risk management should be carried out effectively. Various studies have shown the importance of risk management in meeting project targets like quality, time, and budget [24]. Development ventures are defined by their fluctuating 
degrees of uniqueness and multifaceted nature, the dynamic association of numerous partners, capital seriousness, dynamic situations, long generation terms, and varying climatic conditions [30]. Risks and vulnerabilities are for sure present in all construction projects from commencement to the accomplishment of the projectirrespective of its size, complications involved, and location of the project.

According to [29] revealed that on his study "construction risk in construction industry of the India".93 risk factors were recognized by reviewing literature and these risk factors were listed under various subgroups. All these risk factors were included in the questionnaire and were filled by 15 respondents having experience of more than 20years in the Indian construction industry. For analysis purposes, fuzzy Analytical Hierarchy Process (AHP) was used.

The risk was divided into two groups: the first group includes contractor, project manager, owner, resourcespecific risk, and other group includes risk related to environment, consultant, and contract-clause. The mitigation measures suggested in this paper are useful if applied in a proper manner, it can increase the chances of positive outcomes. According to [27] revealed that risk identification is a good methodology in construction. This research is based on the Chile construction industry which shows both, owners, as well as contractors, never use risk management practices properly which results in a negative outcome and losses. In this paper knowledge-based approach is used and a three-fold methodology is proposed consisting of, risk management model, its assessment, and the use of a best practices model.

Initial conclusion was that risk management is still very unsuccessful due to lack of knowledge of risk involved in the construction practices. The use of the proposed approach will help contractors and clients to deal with risk in a better way and avoid losses. Further, this risk management model can be improved by taking more things into account depending on a particular project or specific location. According to [32] examined risk identification practice in construction industry of Nigeria. Construction plays an important role in enhancing economic growth. Every construction project some sort of risks. These risks cannot be removed and can only be managed. For this study quantitative approach was used as it is based on experience, knowledge, opinion, beliefs of an expert in the field. A total of two-hundred questionnaires were sent and only one-fifty was valid for the analysis. Statistical Package for the Social Sciences was used for the analysis of data using factor analysis approach. The results show that risk can be managed by proper identification of risk, its management, and control. Risk mitigation measures also play an important role in successful completion of project.

\section{A. Statement of the Problem}

Project failures in developing countries during the implementation phase are becoming of great concern to citizens and governments. During this stage project implementation is characterized by inadequate resources, improper priorities, and poor assessment of targets, wrong scheduling, inadequate project identification, formulation and design and faulty conceptualization of policy [5]. Previous studies that have been conducted have attempted to bring various outstanding issues in the construction industry to light. [33] In his study on "the relationship between firm performance and strategic planning in the civil engineering construction sector among firms based in Nairobi, Kenya." The findings revealed that elements of strategic planning in use in these firms, although the findings varied greatly from one firm to another. According to [18] did a study on use of quality management practices in large building construction firms in Kenya.

The findings insulate that the use of various quality management practices, with the traditional low-innovation practices being the most common. However, there were no significant differences in terms of preferences for the various quality management practices. According to [22] $70 \%$ of implemented construction projects exceed their contractual period by $50 \%$. According to [2] they found that in ability of contractors to understand contract conditions increased the contract periods between 10\%-30\%.

Machakos County Government remains the main implementer of capital projects and the implementing agency of exchequer funded building construction projects others include the national government building projects, CDF funded school projects, hospitals, and health centers. The factors influencing implementation of these infrastructure projects have not yet been adequately investigated in devolved governments. Little research has been conducted on risk identification in construction projects in Machakos County in relation to risk identification. It was against this background that the study sought to investigate the influence of risk identification on the performance of exchequer funded building construction projects in Machakos County, Kenya.

\section{B. Objective of the Study}

The objective of the study was to examine the influence of risk identification on the performance of exchequer funded building construction Projects in Machakos County, Kenya.

\section{Research Hypothesis}

The following Null Hypothesis was tested:

$\mathbf{H}_{\mathbf{0}}$ : There is no significant relationship between risk identification and performance of exchequer funded building construction Projects in Machakos County, Kenya.

\section{LITERATURE REVIEW}

Risk management process is categorized into three main sections which are risk identification, risk response and risk analysis. Risk identification stands as the vital process in the risk management chain since it affects the entire risk management process [11]. According to [19], proper risk identification helps the organization to obtained detailed information about the progress of the project and provides a platform for decreasing uncertainty which makes it easier to analyze identified risks.

Various tools and techniques are employed in risk identification process of which only a few are utilized in construction industry. Expert judgement is one of the 
techniques used in risk identification process. It extracts information from experienced project managers, stakeholders, or project specialist using an unstructured, structured, or semi-structured interview [20]. The information obtained from the interview aids in avoiding similar risks which have attendance of reoccurring [17]. According to [7] Expert judgment is one of the significant sources of data gathering and risk identification since it obtains information from experienced staff in the project.

However, [9] disagrees with [7] findings claiming that the information obtained from expert judgement lacks familiarity since the tools and techniques used are unfavorable and that the time frame for conducting the interviews are limited. In this case, many organizations prefer using traditional risk identification methods such as use of checklists and brainstorming.

Brainstorming is one of the traditional methods that is used in projects to identify risk. It extracts risk information from group of experts who freely express their opinion in order to remedy hazards and failure modes. (British Standards (BS) 31010, 2010) defines brainstorming as "inspiring and encouraging free-flowing conversation amongst a group of informative people to discover likely failure manner and linked hazards, risks, formula for decisions and/or options for action." From this definition we can conclude that brainstorming is an excise that takes information from a wider range of opinions from different groups.

Subsequently, brainstorming has many advantages compared to other risk identification techniques. For example, it is time saving, it is cost effective, it provides group thinking capacity and last but not least it facilitates wider identification of risks and extraordinary solutions. However, the use of traditional methods of risk identification in construction projects is still a mountain climb since construction projects gets more complex and dynamic everyday thus require advanced risk identification methods [25].

Another method of risk identification is the use of checklist. It consists of a list of items that are marked Yes or No and it is harmoniously utilized by individual, a group or in an interview by a project member [20]. According to [7] risk identification checklist can be formulated by bringing together information from historical events and knowledge accumulated from previous similar projects. Although it is easy to develop a checklist, it is still impossible to develop and exhaustive one hence caution should be taken for items that are not in the list. To add to this, the checklist should be reviewed frequently during project closure to increase its effectiveness on future projects.[7]. Checklist has limited advantages compared to its disadvantages. It is generally time consuming and it is tedious. According to [10] in his study to "Investigate the risk identification and risk management of construction risks in Malaysia." He found out that financial risks and time related risks had the largest effect on construction projects in terms of occurrence. He later on concluded that one of the main risk management strategy was to equip project staff with necessary risk management skills through trainings.
Scenario building involves identifying the risk catalyst, planning risk mitigation, and anticipating the effect of risk on the project. It ideally relays on information from past experience. This method of risk identification is clearly very different from the rest since the risks are continuously reorganized. It also looks at the project in two different dimensions in which all the anticipated risks are clearly noticed before they occur. Scenario building is majorly dominated by the imaginary scenarios which represents the porotype of the logical construction of each project together with the results [20].

Unlike expert judgment, Delphi technique obtains detailed information about future events from a group of experts. This information is detailed since it comes from expert panel who are creative, experienced and have unstructured knowledge of the anticipated events. It employs systematic collection and vivid comparison of conclusions from anonymous participants who channel their thoughts in a specific subject. Written responses are heavily utilized instead of traditional physical meetings. It also utilizes questionnaires which are carefully prepared and piloted before actually using them [20]. According to [7] in his study he further clarifies that after the collection of information from the questionnaire, each expert is anonymously given opinion of all other experts of which he/she is to draw conclusion from the information after which the conclusions made are distributed anonymously to all experts so that a final conclusion can be arrived at.

Studies recently done in Tanzanian indicate that the construction industry is full of frequent cost increases and delays in the delivery of projects [14]. They also assert that in order to step up the chances of project success and improve the overall performance of projects risk management strategies must be adopted and implemented. [14] conducted a study that aimed at "determining the causes and effects of delays and disruptions in Tanzanian construction projects". Their findings give credence to the observation that despite the quest of the Tanzanian construction industry to remain competitive, low capacity and capability of the locally registered contractors and consultants resulting from weak resource base and inadequate experience are the risks that cause disruptions and delays. The studies have indicated that practitioners are able to identify the risks that have an effect on the projects objectives, but there is a lack of implementation as to the planning, coordination and directing of these risks and their risk financing activities. This postulates that they have failed to grasp the importance of risk management in successful project delivery [14].

\section{Theoretical Framework}

Various theories may apply in regard to risk management practices. Agency theory was integrated with risk identification variable. According to Agency theory, firms can be said to be a web of contracts between capital holders. In agency relationship, one or more entities called principals engage the services of one or more individuals called agents to carry out services or they entrust decision making power to the agents. According to [13] the theory explains a possible difference in the goals of shareholders, management and debt holders occasioned by 
disproportionate distribution of earnings. This can lead to the firm underestimating the impact of risks and engaging in projects that do not result in profit to the organization. The firm's value can thus be influenced by the hedging policies [28].

In corporate risk management, implementation of motivational factors has been examined in a few studies with negative effects. Where the traditional equity-owner are nonexistence, the role of assuming residual risk and guarantee of debt repayment, project-financing plans are frequently accompanied by comprehensive and complex contracts which specify the exact nature and duration of the relationships between various participants in the project.

It becomes necessary therefore, to carefully identify the risks likely to occur over the project duration, from conception to operation. According to [12] "managing risk identification the project guarantor or financial advisor can design a matrix of project participants, the risk components associated with the project, identify risk allocation and the various contractual agreements which allocate risk agency. Risks may be reduced or eliminated by the competition between project managers in managerial labor markets. As project size increases, the two functions usually attributed to the project manager; management and risk bearing, may be treated as naturally separate factors of production within a set of contracts known as the project managed by the project management team. Although individual project stake-holders act from self-interest, they realize that their own individual destinies depend, to some extent, on the success of the project management team in its competition with other project management teams.

As the number of project stakeholders increases, the potential agency incentive problems, associated with the separation of ownership and control of the project, would tend to be resolved by the discipline exerted on project managers by managerial labor markets both within and outside the project". The study utilized this theory to outline how the contractors (agent) influence the performance of projects in case of a dispute between the contractor and the client. This study utilized agency theory as a risk management paraphernalia to set the required threshold for the management contractors (agent) to ensure they perform effectively. This was the main theory this study used to show the integral relationship between the contractor (agent) and the client.

\section{Conceptual Framework}

\section{Independent Variable}

\begin{tabular}{|c|c|}
\hline $\begin{array}{l}\text { Risk Identification } \\
\text { - Expert judgment } \\
\text { report } \\
\text { - Checklist } \\
\text { - Scenario } \\
\text { Building } \\
\text { documents } \\
\text { - Delphi technique }\end{array}$ & $\begin{array}{l}\text { Performance of } \\
\text { exchequer funded } \\
\text { Building construction } \\
\text { projects } \\
\text { - Project completion } \\
\text { in time } \\
\text { - Cost efficiency } \\
\text { - Quality of } \\
\text { construction works }\end{array}$ \\
\hline
\end{tabular}

Fig. 1. Conceptual Framework.

Conceptual framework of this research is intended to determine the influence of risk identification on the performance of exchequer funded building construction Projects in Machakos County, Kenya. There are four major indicators identified from the conceptual framework that measure the performance of exchequer funded building construction projects.

\section{RESEARCH METHODOLOGY}

The study employed descriptive survey design. After collection of data using questionnaires, descriptive statistics is used to obtain statistical information of aspects of a phenomenal being studied. Five point Likert scale was used to quantitatively analyze qualitative data. The study population consisted of all contractors who are under National Construction authority (NCA) in Machakos County. NCA operates under formal organizational dimensions which aids in the criteria for assigning contractors different projects in Kenya hence it was picked as the best sample to represent all construction industry. According to [6] "population studies are more representative because everyone has equal chance to be included in the final sample that is drawn."

A sample is a small group or a population that represents the entire population while sampling refers to the process of selecting a sample that has characteristic of the entire population. For a target population that exceeds a hundred respondents, sampling is more effective for research purposes. A sample is utilized to avoid wastage by being too small or too large and hence gives confidence to the study outcome [15]. This study had a sample population of 232 respondents which was determined by calculating the target population of 532 with a $95 \%$ confidence and an error of 0.05 using the below formula taken from [15].

$$
\mathrm{n}=\mathrm{z}^{2} \text {.p.q. } \mathrm{N} /\left\{\mathrm{e}^{2}(\mathrm{~N}-1)+\mathrm{z}^{2} \cdot \mathrm{p} \cdot \mathrm{q}\right\}
$$

where

$\mathrm{N}=$ Size of population and given 585 .

$\mathrm{z}=1.96$ (desired confidence level is $95 \%$ and value obtained from table).

$\mathrm{p}=0.5$ (sample proportion).

$\mathrm{q}=0.5\{(1-0.5)$ or $(1-\mathrm{p})\}$.

$\mathrm{e}=5 \%$ or 0.05 (precision rate or acceptable error).

Thus,

$$
\begin{gathered}
\mathrm{n}=\left\{(1.96)^{2} \times(0.5) \times(0.5) \times 585\right\} /\left\{(0.05)^{2}(585-\right. \\
\left.1)+(1.96)^{2} \times(0.5) \times(0.5)\right\} \\
\mathrm{n}=561.834 / 2.4204=232
\end{gathered}
$$

TABLE 1: SAMPLING FRAME

\begin{tabular}{cccc}
\hline Category & Total Population & Sample Size & Percentage \% \\
\hline NCA 1 & 18 & 7 & 3.0 \\
NCA 2 & 12 & 5 & 2.2 \\
NCA 3 & 13 & 5 & 2.2 \\
NCA 4 & 30 & 12 & 5.2 \\
NCA 5 & 43 & 17 & 7.3 \\
NCA 6 & 124 & 49 & 21.1 \\
NCA 7 & 106 & 42 & 18.1 \\
NCA 8 & 239 & 95 & 40.9 \\
Total & 585 & 232 & 39.7 \\
\hline
\end{tabular}

Stratified proportionate random sampling was employed to select those who were to participate in the study. 
Stratified random sampling was the best sampling method for this survey due to its unbiased nature of grouping heterogeneous populations to homogenous subsets of which individual subsets are selected to ensure representativeness. According to [15], "a stratified random sampling is used where the population embraces a number of distinct categories; the frame can be organized by these categories into separate "strata." Each stratum was then sampled as an independent sub-population, out of which respondents can be randomly selected." In this study the population is stratified into eight (8) distinct strata and the sample was drawn from these eight (8) strata. Selection of contractors from each stratum was based on simple random sampling.

Closed ended questionnaires were used to collect data since the questionnaires are always cost effective when collecting data from a large sample group. The researcher appointed data collection assistance who aided in the distribution of the questionnaires and at one point they aided in interpreting the questions to the respondents who did not comprehend the questions. Piloting was conducted to ascertain the reliability and validity of the instruments before they were actually used to collect data. Validity evaluates whether the research instrument measures what it intends to measure. There are various types of validity, but this study utilized content and construct validity. According to [3] "Pilot study is a trial run, done in preparation for the main study. This helped in the developing and pre-testing of the research instruments. It also emphasizes the role of piloting in ascertaining the validity and reliability of research instruments.

The research instruments were pretested using 23 respondents as per recommendations by who observe that a successful pilot study will use 1 percent to 10 percent of the actual sample size. For large samples, the lower percentage is used while the converse is true for small samples. Since the sample size is small, the larger value of 10 percent was used in pre-testing." The pilot testing was conducted among NCA listed firms in Machakos County. The researcher selected sample group of 23 individuals to test the reliability of the instrument. Cronbach's Alpha which has values ranging from 0 and 1 in which reliability increases with increase in value was used to measure reliability of the instruments. According to [21] "a coefficient of 0.7 is acceptable as a rule of thumb. Data collected and analyzed during piloting was not included in the actual study." Computation of the Cronbach's Alpha was as follows:

$$
\alpha=\kappa / \kappa-1 \times\left[1-\sum(\mathrm{S} 2) / \sum \mathrm{S} 2 \mathrm{sum}\right]
$$

where

$\alpha=$ Cronbach's alpha.

$\kappa=$ Number of responses.

$\sum(\mathrm{S} 2)=$ Variance of individual items summed up.

$\sum$ S2 $=$ Variance of summed up scores.

The researcher sought research authorization permit from University of Nairobi and National Commission for Science, Technology and Innovation (NACOSTI), then reported to the respective head departments in Machakos County to seek authorization from the administration, further the researcher took time to build relationship with the respondents and set dates as well as time when the respondents start filling the questionnaires as well as conducting interview. On the agreed dates, the researcher issued the questionnaires to the respondents for the aim of collecting data. The respondents were given fourteen days to answer the items in the questionnaires that were collected by the researcher after the fourteen days period. Primary information from the field was altered first. Coding was done to make an interpretation of question reactions into particular classifications.

Accordingly, information from survey was coded and signed in the PC utilizing Statistical Package for the Social Sciences version 25.0.

Clarifying insights include the use descriptive statistics (rates), measures of focal propensity and scattering (mean and standard deviation individually). Frequency tables were utilized to exhibit the information for simple examination. The inferential test was Spearman's product-moment correlation coefficient. Spearman's product-moment correlation coefficients a measure of the strength of a linear association between two variables that is independent variables and the dependent variables. Spearman's correlation coefficients range from -1 to +1 . Negative values indicate negative correlation and positive values indicates positive correlation where Spearman's coefficient $<0.3$ indicates weak correlation, Spearman's coefficient $>0.3<0.5$ indicates moderate correlation and Spearman's coefficient $>0.5$ indicates strong correlation. Multiple linear regression analysis was used to estimate the relationships between a dependent variable and one independent variable. It can be utilized to predict the change in the dependent variable when a change is introduced on independent variable. The formula for multiple linear regression analysis is presented below.

$$
\mathrm{Y}=\mathrm{a}+\mathrm{b} X 1+\epsilon
$$

where

$\mathbf{Y}$ - Performance of construction projects.

$\mathrm{X} 1$-Risk identification.

a - Intercept.

b-Slopes and.

c- Error term.

For Risk identification stated research objective, a hypothesis was formulated, and corresponding correlation model was developed since the relationship to be tested was linear. ANOVA test was conducted to find out if the survey was significant. This helped the researcher to reject the null hypothesis or accept the alternate hypothesis. The null hypothesis was rejected for values of $\mathrm{P}=0.00<0.05$.

\section{RESEARCH FINDINGS AND DISCUSSIONS}

\section{A. Questionnaire Return Rate}

Table 2 shows the results on the response rate of the respondents.

TABLE 2: RESPONSE RATE

\begin{tabular}{ccc}
\hline & Frequency & Percentage $\%$ \\
\hline Category & 175 & 75.4 \\
Responded & 57 & 24.6 \\
Not responded & 232 & 100 \\
Total & & \\
\hline
\end{tabular}


The study targeted 585 contractors registered with National Construction Authority (NCA) in Machakos County while the sample size was 232 respondents. Out of the 232 questionnaires sent to all respondents, 175 were filled and returned, which represents $75.4 \%$ response rate as shown in table 2. According to Babbie (2012), a response rate of $50 \%$ and above was adequate for data analysis. Therefore, the response rate of $75.4 \%$ was adequate and acceptable for drawing conclusions on the study. All constructs and the composite Cronbach's Alpha showed that the value of Cronbach's Alpha were above the suggested value of 0.7. A Cronbach's Alpha of 0.816was obtained. According to Mugenda (2008) Coefficient of 0.7 is a commonly accepted rule of thumb that indicates acceptable reliability hence the research instrument was reliable.

\section{B. Distribution of Respondents by their NCA Category}

The researcher sought to establish the distribution of the respondents by their NCA category. The respondents were required to state their NCA Category and response were analyzed and presented in Table 3.

TABLE 3 DISTRIBUTION OF RESPONDENTS BY THEIR NCA CATEGORY

\begin{tabular}{ccc}
\hline $\begin{array}{c}\text { NCA registration } \\
\text { category }\end{array}$ & Frequency & Percentage \\
\hline NCA 1 & 4 & 2.3 \\
NCA 2 & 5 & 2.9 \\
NCA 3 & 4 & 2.3 \\
NCA 4 & 10 & 5.7 \\
NCA 5 & 13 & 7.4 \\
NCA 6 & 41 & 23.4 \\
NCA 7 & 36 & 20.6 \\
NCA 8 & 62 & 35.4 \\
Total & $\mathbf{1 7 5}$ & $\mathbf{1 0 0 . 0}$ \\
\hline
\end{tabular}

Table 3 shows that NCA1 were $4(2.3 \%)$, NCA2 were $5(2.9 \%)$, NCA3 were $4(2.3 \%)$, NCA4 were $10(5.7 \%)$, NCA5 were $13(7.4 \%)$, NCA6 were $41(23.4 \%)$, NCA7 were 36(20.6) while NCA8 were 62(35.4\%). This shows that NCA8 were the majority.

\section{Risk Identification}

The respondents were requested to respond to the various items that sought to establish the extent to which level of risk identification influence performance of exchequer funded building construction projects in Machakos County, Kenya and various statements of risk identification were examined.

Theywere given various items that were rated on a five point Likert scale ranging from 5-Strongly Agree; 4-Agree; 3- Neutral; 2- Disagree; and 1- Strongly Disagree (1). The findings were shown in Table 4.

Table 4 shows the results of the respondents on the level of agreement on risk identification and performance of exchequer funded building construction projects.

In the descriptive analysis, the Composite mean for this section stands at 3.55 with a standard deviation of 1.142 .

This reveals that the respondents strongly agreed with risk identification as the panacea for risk management in construction of buildings. The item 'Project team reviews checklist during project closure to improve its' use on future projects' was found to have the highest mean of 3.81 and standard deviation of 0.854 .
TABLE 4: RISK IDENTIFICATION

\begin{tabular}{lccc}
\hline Statement & N & Mean & SD \\
\hline $\begin{array}{l}\text { Expert judgment interview is } \\
\text { conducted by experienced project } \\
\text { stakeholders. }\end{array}$ & 175 & 3.67 & .966 \\
$\begin{array}{l}\text { Project team reviews checklist } \\
\text { during project closure to improve its } \\
\text { use on future projects. }\end{array}$ & 175 & 3.81 & .854 \\
$\begin{array}{l}\text { Risks were identification from past } \\
\text { experience. }\end{array}$ & 175 & 3.70 & .930 \\
$\begin{array}{l}\text { Inadequate supervision team. } \\
\text { Actual quantities in Bills of } \\
\text { quantities are different from contract } \\
\text { quantities. }\end{array}$ & 175 & 3.26 & 1.207 \\
$\begin{array}{l}\text { Legal disputes during construction } \\
\text { among the parties. }\end{array}$ & 175 & 3.17 & 1.174 \\
$\begin{array}{l}\text { An opinion consensus about future } \\
\text { events is obtained from a group of } \\
\text { experts (Delphi technique) } \\
\text { Composite mean and standard } \\
\text { Deviation }\end{array}$ & 175 & 3.52 & 1.193 \\
\hline
\end{tabular}

This was followed by 'Risks were identification from past experience' (mean=3.70, S.D=0.930). 'Expert judgment interview is conducted by experienced project stakeholders' (mean=3.67, S.D=0.966). 'An opinion consensus about future events is obtained from a group of experts (Delphi technique)' (mean=3.52, S.D=1.193). 'Actual quantities in Bills of quantities are different from contract quantities' (mean=3.44, S.D=1.137). 'Inadequate supervision team' (mean=3.26, S.D=1.207). 'Legal disputes during construction among the parties' (mean=3.17, S.D=1.170).

In regard to (H0) hypothesis "There is no significant relationship between risk identification and performance of exchequer funded building construction Projects." the results in the Table below were relied upon in accepting or rejecting the stated hypothesis.

The respondents were required to answer a set of questions in relation to performance of exchequer funded building construction projects. The findings showed that there was a significant relationship between risk identification and performance of exchequer funded building. Majority of the respondents attested that during project closure the project team examine their checklist to improve its relevance on future projects. This concurs with the findings by [20] who attested that "Checklist consists of a list of items that are marked as yes or no and could be used by an individual project team member, a group or in an interview."

Risk Identification in the construction is unavoidable because of the complex dynamic environment in which construction work has to be performed [1]. As construction activities are uncertain in nature, therefore, studies affirm that construction is a profoundly hazard inclined industry [34]. For the success accomplishment of project objectives and targets, risk should be managed in an effective manner. Risk management has been known as a vital tactic to meet project targets like time, budget, and quality [24].

Development ventures are defined by their fluctuating degrees of uniqueness and multifaceted nature, the dynamic association of numerous partners, capital seriousness, dynamic situations, long generation terms, and varying climatic conditions [30].

Risks and vulnerabilities are for sure present in all construction projects from commencement to the 
accomplishment of the project-irrespective of its size, complications involved, and location of the project.

TABLE 5: RISK IDENTIFICATION REGRESSION MODEL SUMMARY

\begin{tabular}{ccccc}
\hline Model & $\mathrm{R}$ & $\mathrm{R}$ Square & $\begin{array}{c}\text { Adjusted R } \\
\text { Square }\end{array}$ & $\begin{array}{c}\text { Std. Error of the } \\
\text { Estimate }\end{array}$ \\
\hline 1 & $.199^{\mathrm{a}}$ & .040 & .034 & 4.69166 \\
\hline
\end{tabular}

a. Predictors: (Constant), Risk identification.

Dependent: Performance of exchequer funded building construction Projects

In this case, the adjusted R-squared is 0.034 . This means that risk identification variable explains $3.4 \%$ variations in the dependent variable (Performance of exchequer funded building construction Projects) while the rest are explained by the error term.

TABLE 6: RISK IDENTIFICATION ANOVA ${ }^{\mathrm{a}}$

\begin{tabular}{cccccc}
\hline Model & $\begin{array}{c}\text { Sum of } \\
\text { squares }\end{array}$ & Df & $\begin{array}{c}\text { Mean } \\
\text { Square }\end{array}$ & F & Sig \\
\hline Regression & 156.759 & 1 & 156.759 & 7.122 & $.008^{\mathrm{b}}$ \\
Residual & 3308.018 & 173 & 22.012 & & \\
Total & 3964.777 & 174 & & & \\
\hline
\end{tabular}

a. Dependent Variable: Performance of exchequer funded building construction Projects.

b. Predictors: (Constant), Risk identification.

Risk identification influences performance of exchequer funded building construction projects at 0.008 significant level thus the model was significant.

The findings for the ANOVA on risk identification indicates a numerator for whose degrees of freedom $(\mathrm{df})=1$, denominator $\mathrm{df}=174$. The above findings show F-test to determine whether the model had a good fit for the data. The F-Test $(\mathrm{F}=7.122, \mathrm{P}=0.008<0.05)$. From these findings, the regression model is significant since $\mathrm{P}$ value $=0.008$ which is less than $5 \%$.

This provides a significant level of explanation of the relationship between risk identification and Performance of exchequer funded building construction Projects.

TABLE 7: RISK IDENTIFICATION COEFFICIENTS

\begin{tabular}{ccccccc}
\hline & \multicolumn{2}{c}{$\begin{array}{c}\text { Unstandardized } \\
\text { Coefficients }\end{array}$} & $\begin{array}{c}\text { Standardized } \\
\text { Coefficients }\end{array}$ & \multirow{2}{*}{ T } & Sig \\
\cline { 2 - 4 } & $\mathrm{B}$ & $\begin{array}{c}\text { Std. } \\
\text { Error }\end{array}$ & Beta & & \\
\hline $\begin{array}{c}\text { Constant } \\
\text { Risk }\end{array}$ & 21.371 & 2.208 & & 9.677 & .000 \\
identification & .237 & .089 & .199 & 2.669 & .008 \\
\hline
\end{tabular}

Dependent Variable: Performance of exchequer funded building construction Projects.

$$
\left(\mathrm{Y}=21.371+0.337 \mathrm{X}_{1}+\varepsilon\right)
$$

The study outcome indicates that risk identification leads to performance of exchequer funded building construction project by a factor of 0.237 with $\mathrm{P}$ value of 0.008 . This is statistically significant since the P-value is less than 0.005 with reference to $5 \%$ level of significance and $95 \%$ level of confidence. The study therefore rejects the null hypothesis implying that there is significant influence of risk identification on performance of exchequer funded building construction Projects.

\section{CONCLUSION}

From the study findings, majority of the respondents confirmed that risk identification influences the performance of exchequer funded building construction projects. This was shown by the majority who agreed that project team reviews checklist during project closure to improve its' use on future projects influences the performance of exchequer funded building construction Projects in Machakos County, Kenya with a mean of 3.81. Since $\mathrm{P}$ calculated is less than 0.05 level of significance $(\mathrm{P}=0.008<0.05)$, the study rejects the null hypothesis and concludes that there is significant influence of risk identification on performance of exchequer funded building construction Projects.

This study therefore concludes that risk identification is a major contributor towards the performance of exchequer funded building construction Projects.

\section{RECOMMENDATIONS}

i. On risk identification, the study recommends that there is need for adequate supervision team, actual quantities in Bills of quantities needs to be the same from contract quantities, legal disputes during construction among the parties and opinion consensus about future events need to be obtained from a group of experts (Delphi technique). This will enhance performance of exchequer funded building construction projects.

ii. The current study should be developed in future in order to outline other factors that possibly influence the performance of exchequer funded building construction projects.

iii. Similar research should be conducted in other county governments and national government projects in Kenya to confirm whether the outlined factors can be confined to influence the performance of exchequer funded building construction projects.

\section{REFERENCES}

[1] Akintoye, A. S. (2017). Risk analysis and management in construction. International Journal ofProject Management, 15(1), 31-38.

[2] Ali, A. S. \&Kamaruzzaman, S. N. (2010). Cost Performance for Building ConstructionProjects in Klang Valley. Journal of Building Performance.

[3] Babbie. (2012). The Practice of Social Research. (1. Edition, Ed.) Cengage Learning.

[4] Babbie, E. R. (2012). The Practice of Social Research. (1. Edition, Ed.) Cengage Learning.

[5] Bank, W. (2012). World Development Indicators, Washington, D.C. World Bank Publications .

[6] Bryman, A. (2016). Social Research Methods. London. (5. ed, Ed.) Oxford University Press.

[7] Chihuri, S. \&. (2011). Managing Risk for Success in a South African Engineering and Construction Project Environment . South African Journal of Industrial Engineering , 21(2), 63 -77.

[8] Connaway, L. S., \& Powell, R. R. (2010). Basic research methods for librarians . Littleton, CO. (5thed, Ed.) Libraries Unlimited.

[9] Forbes, D. S. (2015). Tools for selecting appropriate risk management techniques in the built environment . Construction Management and Economics, Vol. 26(11): 1241-1250.

[10] Goh, D. S.-R. (2013). The Identification and Management of Major Risks in the Malaysian Construction Industry. Journal of Construction in Developing Countries, 18(1), 19-32.

[11] Gray, C. F. (2010). Project Management . (4. edition, Ed.) The Managerial Process McGraw-Hill/Irwin .

[12] Hamimah. (2014). An assessment of risk management in joint 
venture (JV) in Malaysia. Asian Social Science, 4(6), 99-106.

[13] Jensen, M. and Meckling, W. . (1976). Theory of the firm: managerial behavior, agency costs and ownership structure. Journal of Financial Economics, 3, 305-360.

[14] Kikwasi, G. J. (2014). Causes and Effects of Delays and Disruptions in Construction Projects in Tanzania. Australasian Journal of Construction Economics and Building, Conference Series, 1(2), 52-9.

[15] Kothari, C. R. (2009). Research Methodology: Methods and Techniques. New Delhi: . New Age Publications.

[16] Kuang, Z. (2011). Risk Management in Construction Projects. Application of Risk Management in Construction Period. Bachelor of Architectural Technology and Construction Management.

[17] Mahendra et al. (2013). A Study of Risk Management Techniques for Construction Projects in Developing Countries. International Journal of Innovative Technology andExploring Engineering (IJITEE) , 3, 5.

[18] Mandere, A. N. (2006). A Survey of Quality Management Practices in the Large KenyanBuilding Construction Firms, Unpublished MBA Thesis, University of Nairobi,Nairobi, Kenya.

[19] Merna, T. a.-T. (2013). Corporate risk management. an organizational perspective.

[20] Morano C.A.R et al. (2013). , Martins C.G, Ferreira M.L.R 'Application of techniques for the identification of risk in the E \& P ventures. Engevista, 8(2),120-133.।.

[21] Mugenda, O. M., \&Mugenda, A.G. (2009).ResearchMethods.QualitativeandQuantitativeApproach.Nairo bi: Acts Press.

[22] Nyangilo, A. O. (2012). An assessment of the organization structure and leadership effects on construction projects' performance in Kenya: a case study of public building projects within Nairobi region, Thesis. University of Nairobi

[23] Okogbuo, F. U. ( 2015). Project Risk Management Issues in the Nigerian Construction Industry. International Journal of Engineering and Technical Research (IJETR), 3(1): 217-232.

[24] Radya, S. \&. (2019). Managing production profile uncertainties in P field LLP project economic evaluationusing factorial design. Journal of Administrative and Business Studies, 5(2), 99-109.

[25] Raz, T. a. (2010). Use and benefits of tools for project risk management. International Journal of Project Management, Vol 19(1): 9-17.

[26] Saunders, M., Lewis, P. \&Thornhill, A. (2007). Research Methods for Business Students,

[27] Serpella, A. F. (2014). Risk management in construction projects. Aknowledge-based approach.Procedia - Social and Behavioral Sciences, 119, 653-662.

[28] Smith, C. S. (1985). The Determinants of Firm's Hedging Policies. Journal and Quantitative Analysis, Vol. 20, No. 4, pp. 391-405.

[29] Subramanyan, H. S. ( 2012). Construction project risk assessment: Development of modelbased on investigation of opinion of construction project experts from India. Journal of Construction Engineering and Management, 138(3), 409-421.

[30] Taroun, A. (2014). Towards a better modelling and assessment of construction risk: Insights from a literature review. International Journal of Project Management, 32(1), 101-115.

[31] Tchankova, L. (2012). Risk identification: basic stage in risk management. Environmental Management and Health, 13(3):290297. Towers Perrin. Towers Perrin Risk and .

[32] Ugwu, M. C. (2019). Evaluation of risk management practice in the Nigeriaconstruction industry. Modular and Offsite Construction (MOC) Summit Proceedings, 373-380.

[33] Yamo, J. (2006). Strategic Planning and Performance of Civil Engineering ConstructionFirms in Nairobi, Unpublished MBA Thesis, University of Nairobi, Nairobi, Kenya.

[34] Zeng, J. A. (2018). Application of a fuzzy based decision making methodology to constructionproject risk assessment. International Journal of Project Management, 25(6), 589-600. 